\title{
Endoscopic findings in patients with refractory dyspepsia at A Tertiary Care Hospital in Peshawar, KPK Province, Pakistan.
}

1. FCPS

Senior Registrar Medicine \& Allied

Rehman Medical Institute,

Peshawar.

2. MRCP

Consultant Gastroenterologist

Rehman Medical Institute,

Peshawar.

3. MBBS

House Officer Medicine \& Allied

Rehman Medical Institute,

Peshawar.

4. FRCP

Consultant Physician Medicine \&

Allied

Rehman Medical Institute,

Peshawar.

5. MCPS, MPH

Lecturer

Khyber Medical University,

Peshawar.

6. MBBS

Trainee Medicine

Rehman Medical Institute,

Peshawar.

Correspondence Address:

Dr. Wajeeha Qayyum

Department of Medicine \& Allied

Rehman Medical Institute, Peshawar.

drwajeeha13@yahoo.com

Article received on:

28/07/2020

Accepted for publication:

02/09/2020

\section{INTRODUCTION}

Dyspepsia is symptom based diagnosis. A wide spectrum of definitions exist for dyspepsia, but a reasonable one is "epigastric pain or discomfort for at least three months in a patient who does not report predominant heart burn or regurgitation". ${ }^{1}$ The definitive diagnostic test for evaluation of dyspepsia is flexible oesophagogastroduodenoscopy (OGD), which is an invasive procedure carrying a small risk of perforation. ${ }^{2}$

Refractory dyspepsia is a term used to describe dyspeptic symptoms not relieved by acid suppression therapy. ${ }^{3}$ Its prevalence is $7-45 \%$ globally and $8-30 \%$ in Asian population. ${ }^{4,5}$ Oesophagitis, peptic ulcer disease(PUD), pylori infection and carcinomas of stomach and esophagus can present with refractory dyspepsia but they usually make small part in etiology. ${ }^{1}$ In 70-
$80 \%$ of refractory dyspepsia cases OGD is normal; they are classified as having functional dyspepsia (FD). ${ }^{1}$ Functional dyspepsia is the commonest reason of dyspepsia worldwide ${ }^{6}$ and has been defined by Rome IV criteria as "the presence of worrisome postprandial fullness, early satiety, epigastric pain/burning that is thought to originate from the gastroduodenal region in the absence of any organic, systemic or metabolic disease". ${ }^{7}$ Its prevalence is $11-29 \%$ worldwide while in Asia it is $8-23 \%$ prevalent. ${ }^{4,5}$ Refractory dyspepsia is a common condition being addressed very frequently in clinical practice. ${ }^{5}$ It doesn't cause any increase in mortality or morbidity as in $80 \%$ cases it is functional. ${ }^{1}$ However, it imposes considerable effect on patients life and also burdens health care services. $^{5}$

It is difficult to differentiate between organic and functional disease merely on symptoms ${ }^{8}$, and 
even the presence of alarm features are not always helpful. ${ }^{9}$ OGD is not mandated in the management of dyspepsia, however it is the only tool to establish the underlying etiology of dyspepsia, and also to clarify the diagnosis of functional dyspepsia in the absence of any organic findings. ${ }^{1}$ New emerging psychotropic therapies for functional dyspepsia can help these patients once the diagnosis is confirmed. ${ }^{10}$ There are different reviews regarding dyspepsia management and evaluation. Test and treat approach is opted by NICE and American guidelines and OGD is only recommended in patients with ALARM feautures. ${ }^{3,11,12}$ A Dutch study described that initial OGD followed by cause directed therapy caused less economic burden than empiric therapy. ${ }^{13}$

Dyspepsia can be due to multiple pathologies in the GI tract. A systematic review based on nine studies included 5389 participants with dyspepsia. OGD findings showed erosive oesophagitis in $13 \%$ and peptic ulcer disease(PUD) in $8 \%$, cancers of upper Gastrointestinal tract accounted for less than $0.3 \%$ of patients with dyspepsia. ${ }^{14}$ Oesophagitis was more in West as compared to Asian population (25\% vs $3 \%$ ), where as PUD was more common cause of dyspepsia in Asians as compared to Western people. (3\% vs $11 \%) .{ }^{14}$

Keeping in view the geographic and ethnic difference in endoscopic findings of dyspepsia, the data from Pakistan is insufficient to present our population. ${ }^{11,15-17}$ In KPK region only 1 study has been reported in this regard that included only 50 patients, more over they included all patients with dyspepsia and was not specific to refractory dyspepsia. ${ }^{16}$

This study was aimed to note the endoscopic findings in patients with refractory dyspepsia.

\section{MATERIAL \& METHODS}

It was an observational study carried out over a period of 2yrs from March 2017- Feb 2019 after approval from Hospital Ethical committee. All the patients who were referred for endoscopy for refractory dyspepsia were included by consecutive nonprobability sample technique. Patient who had other Gl symptoms along with dyspepsia and also those who were taking drugs (NSAIDs, bisphosphonates, calcium channel blockers, corticosteroids and nitrates) were excluded. Written informed consent was taken from patients. Endoscopy was performed by consultant skilled in technique, visualization up till $2^{\text {nd }}$ part of duodenum was carried out and endoscopic diagnosis was made. Patient's demographic profile and endoscopic diagnosis was noted in a pre designed pro forma.

Dyspepsia was defined as per ROME IV criteria as 1 or more of the following 3 symptoms for 3 months within the initial 6 months of symptom onset: (1) post-prandial fullness, (2) early satiety, and (3) epigastric pain or burning. Patients who didn't respond to 3months treatment with PPI or patients who have had $\mathrm{H}$ pylori eradications were categorized as refractory dyspepsia. ${ }^{3}$

On upper Gl endoscopy, oesophagitis/Gastritis/ duodenitis/gastroduodenitis was defined as mucosal edema and erythema in esophagus/ stomach/duodenum or both. Superficial mucosal defects of $<5 \mathrm{~mm}$ in diameter with flat edges that could be red, yellow or white were termed gastroduodenal erosions and Mucosal breaks of $>5 \mathrm{~mm}$ in diameter were termed as gastroduodenal ulcers. ${ }^{11}$

\section{DATA ANALYSIS}

Data was entered and analyzed through SPSS version 22. Descriptive statistic was calculated for both numerical and continuous variables. For numerical variables percentage and frequency were calculated. For continuous variables mean $\pm S D$ was calculated. Student $T$ test and Chi-square test were used to look for statistical difference where ever indicated. $P$ value $\leq 0.05$ was taken statistically significant.

\section{RESULTS}

A total of 727 patients were included in study. Mean age was $43.09 \pm 15$. of total study population, $51.6 \%(n=375)$ were male while females accounted for $48.4 \% \quad(n=352) .58 .7 \%$ $(n=427)$ were Pakistani and 41.3\% $\quad(n=300)$ belonged to Afghanistan.

Out of a sample of 727 people, the endoscopic 
findings of $54.30 \%(n=395)$ turned out normal with no pathology picked up on OGD. Other endoscopic finding are described in Figure-1.

Table-I illustrates the frequency of the different endoscopic findings in different age groups of the sample. Age stratification showed that reflux oesophagitis was more commonly seen in older age group (56-70yrs) as compared to other age groups. The difference is statistically significant. ( $P$ value 0.01 ). Gastroduodenitis was significantly more common in patients aged between 41-55yrs. ( $P$ value 0.02 ) Patients belonging to younger age group (<25yrs) had significantly higher number of normal OGDs. ( $P$ value $<0.05$ ). No other significant age specific finding was observed.

Table-Il illustrates the gender wise endoscopic findings in patients with refractory dyspepsia. The number of patients with normal OGD was significantly higher in females ( $P$ value $<0.05)$. There was no significant difference between two genders in terms of other OGD findings.

Table-II. Frequency of the different endoscopic findings in different genders

Table-III describes the endoscopic findings in Pakistani and patients from Afghanistan separately. The frequency of normal OGD was significantly higher in patients from Afghanistan as compared to Pakistani. (P value 0.03). There was no significant difference in other OGD findings in both nations.

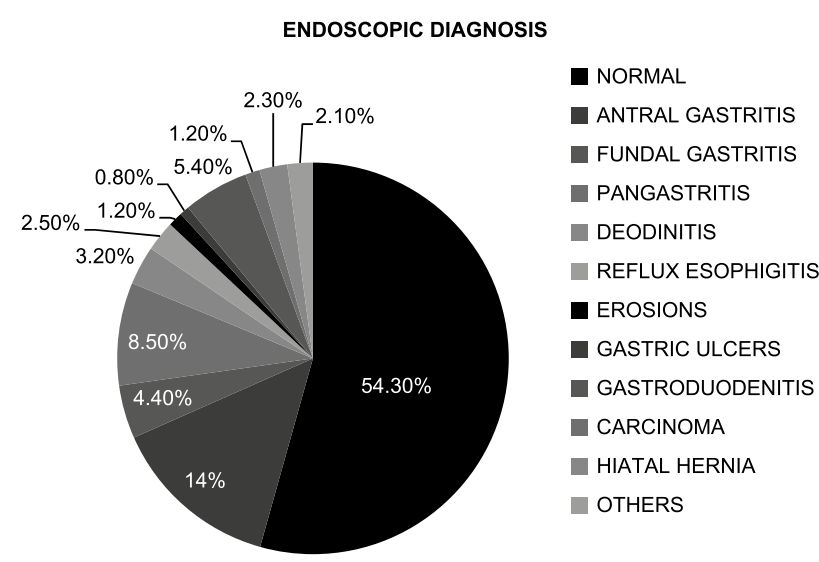

Figure-1. Endoscopic findings of study population

\section{DISCUSSION}

Mean age of our patients was $43.09 \pm 15$. Studies conducted in Asia showed relatively younger patients presenting with dyspepsia as compared to Europe..$^{19,20}$ In a study conducted in India mean age of patients with refractory dyspepsia was $41.45 \pm 15.343 .{ }^{19}$ The mean age of 105 participants was $36.51 \pm 7.26$ year in a study conducted in Bangladesh. ${ }^{20} \mathrm{~A}$ Study from the US noted average age of patients with dyspepsia as $48.4 \pm 12.6 .^{21}$ The mean age of patients was 58 \pm 16.1 years in a study from UK. ${ }^{2}$

Male predominance was noted in our study. Most of the other similar studies conducted in different parts of the world observed female preponderance in patients with dyspepsia.

\begin{tabular}{|c|c|c|c|c|c|c|}
\hline $\begin{array}{c}\text { Endoscopic } \\
\text { Finding }\end{array}$ & $\begin{array}{c}<25 \text { Years } \\
n=86\end{array}$ & $\begin{array}{c}26-40 \text { Years } \\
n=271\end{array}$ & $\begin{array}{c}\text { 41-55 Years } \\
n=218\end{array}$ & $\begin{array}{c}56-70 \text { Years } \\
n=118\end{array}$ & $\begin{array}{c}71<\text { Years } \\
n=34\end{array}$ & P-Value \\
\hline Antral Gastritis & $11(12.8 \%)$ & $38(14 \%)$ & $26(11.9 \%)$ & $21(17.8 \%)$ & $6(17.6 \%)$ & 0.61 \\
\hline Fundal Gastritis & $2(2.3 \%)$ & $13(4.8 \%)$ & $8(3.7 \%)$ & $8(6.8 \%)$ & $1(2.9 \%)$ & 0.55 \\
\hline Pangastrtis & $6(7 \%)$ & $24(8.9 \%)$ & $14(6.4 \%)$ & $13(11.0 \%)$ & $5(14.7 \%)$ & 0.38 \\
\hline Gastroduodenitis & $1(1.2 \%)$ & $11(4.1 \%)$ & $16(7.3 \%)$ & $6(5.1 \%)$ & $5(14.7 \%)$ & 0.02 \\
\hline Duodenitis & $3(3.5 \%)$ & $7(2.6 \%)$ & 7 (3.2\%) & $6(5.1 \%)$ & $0(0.0 \%)$ & 0.58 \\
\hline Reflux Oesophagitis & $0(0.0 \%)$ & $5(1.8 \%)$ & $4(1.8 \%)$ & $8(6.8 \%)$ & $1(2.9 \%)$ & 0.01 \\
\hline Hiatal Hernia & $2(2.3 \%)$ & $6(2.2 \%)$ & $2(0.9 \%)$ & $5(4.2 \%)$ & $2(5.9 \%)$ & 0.22 \\
\hline Erosions & $1(1.2 \%)$ & $6(2.2 \%)$ & $1(0.5 \%)$ & $1(0.8 \%)$ & $0(0.0 \%)$ & 0.43 \\
\hline Gastric Ulcers & $0(0.0 \%)$ & $2(0.7 \%)$ & $2(0.9 \%)$ & $2(1.7 \%)$ & $0(0.0 \%)$ & 0.71 \\
\hline Carcinoma & $0(0.0 \%)$ & $3(1.1 \%)$ & $4(1.8 \%)$ & $2(1.7 \%)$ & $0(0.0 \%)$ & 0.66 \\
\hline Others & $3(3.5 \%)$ & $6(2.2 \%)$ & $4(1.8 \%)$ & $2(1.7 \%)$ & $0(0.0 \%)$ & 0.78 \\
\hline Normal & 57 (66.3\%) & $150(55.4 \%)$ & 130 (59.6\%) & 44 (37.3\%) & $14(41.2 \%)$ & $<0.05$ \\
\hline
\end{tabular}




\begin{tabular}{|c|c|c|c|c|c|}
\hline \multirow{3}{*}{ Endoscopic Finding } & \multicolumn{4}{|c|}{ Gender } & \multirow{3}{*}{ P-Value } \\
\hline & \multicolumn{2}{|c|}{ Male } & \multicolumn{2}{|c|}{ Female } & \\
\hline & $n=375$ & (\%) & $n=352$ & $(\%)$ & \\
\hline Antral Gastritis & 58 & $15.5 \%$ & 44 & $12.5 \%$ & 0.61 \\
\hline Fundal Gastritis & 25 & $6.7 \%$ & 7 & $2 \%$ & 0.55 \\
\hline Pangastrtis & 36 & $9.6 \%$ & 25 & $7.4 \%$ & 0.38 \\
\hline Gastroduodenitis & 23 & $6.1 \%$ & 17 & $4.5 \%$ & 0.06 \\
\hline Duodenitis & 17 & $4.5 \%$ & 6 & $1.7 \%$ & 0.58 \\
\hline Reflux Oesophagitis & 12 & $3.2 \%$ & 6 & $1.7 \%$ & 0.17 \\
\hline Hiatal Hernia & 5 & $1.3 \%$ & 12 & $3.4 \%$ & 0.22 \\
\hline Erosions & 6 & $1.6 \%$ & 3 & $0.9 \%$ & 0.43 \\
\hline Gastric Ulcers & 5 & $1.3 \%$ & 1 & $0.3 \%$ & 0.71 \\
\hline Carcinoma & 7 & $1.9 \%$ & 2 & $0.6 \%$ & 0.66 \\
\hline Others & 9 & $2.4 \%$ & 6 & $1.7 \%$ & 0.78 \\
\hline Normal & 172 & $45.9 \%$ & 223 & $63.4 \%$ & $<0.05$ \\
\hline
\end{tabular}

Table-II. Frequency of the different endoscopic findings in different genders

\begin{tabular}{|c|c|c|c|c|c|}
\hline \multirow{3}{*}{ Endoscopic Findings } & \multicolumn{4}{|c|}{ Country of Origin } & \multirow{3}{*}{ P-Value } \\
\hline & \multicolumn{2}{|c|}{ Afghanistan } & \multicolumn{2}{|c|}{ Pakistan } & \\
\hline & $n=300$ & $\%$ & $n=427$ & $\%$ & \\
\hline Antral Gastritis & 40 & $13.3 \%$ & 62 & $14.5 \%$ & 0.65 \\
\hline Fundal Gastritis & 14 & $4.7 \%$ & 18 & $4.2 \%$ & 0.70 \\
\hline Pangastrtis & 19 & $6.3 \%$ & 43 & $10.1 \%$ & 0.07 \\
\hline Gastroduodenitis & 11 & $3.7 \%$ & 28 & $6.6 \%$ & 0.08 \\
\hline Duodenitis & 10 & $3.3 \%$ & 13 & $3.0 \%$ & 0.82 \\
\hline Reflux Oesophagitis & 4 & $1.3 \%$ & 14 & $3.3 \%$ & 0.09 \\
\hline Hiatal Hernia & 5 & $1.7 \%$ & 12 & $2.8 \%$ & 0.31 \\
\hline Erosions & 4 & $1.3 \%$ & 5 & $1.2 \%$ & 0.84 \\
\hline Gastric Ulcers & 4 & $1.3 \%$ & 2 & $0.5 \%$ & 0.20 \\
\hline Carcinoma & 5 & $1.7 \%$ & 4 & $0.9 \%$ & 0.38 \\
\hline Others & 7 & $2.3 \%$ & 8 & $1.9 \%$ & 0.66 \\
\hline Normal & 177 & $59.0 \%$ & 218 & $51.1 \%$ & 0.03 \\
\hline
\end{tabular}

Table-III. Frequency of the different endoscopic findings in different countries of origin

$61.2 \%$ of patients were females in a study conducted in the $\mathrm{UK},^{2}$ female preponderance at $72.38 \%$ was also noted in Bangladesh. ${ }^{20}$ Studies from Iran, Italy and India also showed female preponderance in dyspepsia. The reason for this difference can be that Pakhtun females are less likely to get medical attention or not willing to undergo procedure as compared to males. ${ }^{24}$

Regarding endoscopic findings, almost half of our patients had normal endoscopic study. This finding is supported by a study carried out in Rawalpindi, Pakistan that reported $58.8 \%$ normal endoscopies with patients with refractory dyspepsia. ${ }^{11}$ A study from USA also reported $50 \%$ normal OGDs in patients with dyspepsia ${ }^{21}$, while in a study carried out in two hospitals in UK showed that $24.4 \%$ patients with dyspepsia had normal OGD. ${ }^{2}$ The lower number of normal OGDs in UK may be explained by the fact that the mean age of study participants in the UK was higher as compared to our study population. (58 vs. 43 years.).

Gastritis was the most common abnormality observed by us in our patients; this finding was supported by a study conducted in Rawalpindi and Bangladesh. ${ }^{11,20}$

It has been shown by a meta analysis that reflux esophagitis is less common cause of dyspepsia in Asia as compared to western countries. ${ }^{1}$ In our study only $2.5 \%$ of our patients suffered from reflux oesophagitis. This finding is also supported by studies conducted in India, Bangladesh and 
Pakistan. ${ }^{11,19,20}$

Hiatus hernia was observed in only $2.3 \%$ patients. A study carried out in India showed this finding in only $1 \%$ of dyspeptic patients undergoing OGD. ${ }^{19}$ On the other hand a study from UK stated $35.6 \%$ population with dyspepsia had hiatus hernia on endoscopy. ${ }^{2}$ The reason for this difference is the well documented fact that prevalence of hiatus hernia is markedly less in Asia as compared to western countries. ${ }^{25}$

Carcinoma was observed only in $1.2 \%$ patients. This finding is supported by studies carried out in UK, Brazil and US. ${ }^{2,12,21}$ Moreover our patients belonged to middle age group in which gastric Cancers are rarely seen. ${ }^{26}$

Although peptic ulcer disease is prevalent in Asia as compare to the Westerncountries ${ }^{1}$ yet we observed very less number $(0.8 \%)$ of patients who had ulcers on OGD. Other studies from south Asia have documented relatively larger number of patients with ulcers.2.3\% in a study from Pakistan ${ }^{11}$, 3\% from India ${ }^{19}, 3.8 \%$ from Bangladesh $^{20}, 5.1 \%$ from Kashmir. ${ }^{27}$ Our this finding is supported by a study from Pakistan and NorthKashmir. ${ }^{11,27}$ The reason may be that patients with large peptic ulcers usually presents with upper Gl bleeding and secondly we included patients with refractory dyspepsia i.e. those who have taken PPI \&/or H Pylori eradication therapy for adequate time to heal ulcers.

Functional dyspepsia (FD) is more commonly seen in Asia as compared to Europe. ${ }^{1}$ Our study showed that $89.8 \%$ of our patients had FD, only $10.2 \%$ had organic dyspepsia. In a study from Pakistan FD was seen in $73.1 \%$ patients ${ }^{11}$, where as a study from Bangladesh documented $68 \%$ of patient suffering from FD. ${ }^{20}$ In India, frequency of FD was shown as $39.1 \%$ and $70.1 \%$ in two different studies. ${ }^{19,28}$

Our study demonstrated significantly higher frequency of functional dyspepsia. This can be explained keeping in view the relationship of functional dyspepsia to psychological stress. ${ }^{1,29,30}$ Prevalence of psychological illnesses in KPK is higher as compared to other areas of Pakistan ${ }^{31}$, especially in young adults. ${ }^{32}$ Similarly, it has been documented that there is high prevalence of depressive illness in Afghan population possibly due to the conflict persisting in their country. ${ }^{33}$

FD was more significantly observed in the female gender, amongst Afghan population and in the younger age group (26-40yrs). All these groups are shown to have higher prevalence of depressive illness that can be translated in the form of psychosomatic disorders. ${ }^{31-33}$ Among other pathological findings, Reflux esophagitis was significantly more in age group 56-70yrs, finding supported by a study from Pakistan. ${ }^{11}$

Our study represents the $1^{\text {st }}$ study from Peshawar, KPK exploring the endoscopic causes of Refractory dyspepsia in a large study population both from KPK and Afghanistan. However, it has some limitations. To begin with, it's a single centered study so the results can't be generalized to the whole population in that area.

Our study highlighted that the major part of refractory dyspepsia is contributed by FD that is more common in young age group, female gender and Afghan population. So these groups should be focused to overcome the disease symptoms as these symptoms usually adversely affect quality of life of patients. Moreover, our study reflects that OGD performed in patients with refractory dyspepsia has not led to the detection of any obvious pathology. Further research is required to promote non invasive investigations/ tools that can guide selection of appropriate patients for endoscopic evaluation.

\section{CONCLUSION}

Our study demonstrated that normal OGD finding was the most common pattern seen in patients with refractory dyspepsia, it was found to be more common in females, young age group and patients from Afghanistan. Among pathological findings reflux oesophagitis was more common in elderly patients. Carcinoma, hiatus hernia and peptic ulcer disease were less common findings. Copyright $\odot 02$ Sep, 2020. 


\section{REFERENCES}

1. Ford AC, Omayyad P. Dyspepsia. BMJ. 2013; 347:f 5059. doi: 10.1136/bmj.f5059.

2. Ching H-L, Hale MF, Sigh R, McAlindon ME. Reassessing the value of gastroscopy for the investigation of dyspepsia. Frontline Gastroenterology. 2018; 9: 6266. doi: 10.1136/flgastro-2017-100838.

3. NICE. Gastro esophageal reflux disease and dyspepsia in adults: Investigation and management: Clinical Guideline CG184. London: NICE, 2009 [updated 2019].

4. Mahadeva S, Ford A. Clinical and epidemiological differences in functional dyspepsia between the East and the West. Neurogastroenterol Motil. 2015; 28(2): 167-174. doi: $10.1111 / \mathrm{nmo} .12657$.

5. Ghoshal UC, Singh R, Chang FY, Hou X, Wong BCY, Kachintorn $U$. Epidemiology of uninvestigated and functional dyspepsia in Asia: Facts and fiction. J Neurogastroenterol Motil. 2011; 17(3): 235-244. doi: 10.5056/jnm.2011.17.3.235.

6. Teriaky A, AINasser A, McLean C, Gregor J, Yan B. The utility of endoscopic biopsies in patients with normal upper endoscopy. Can J Gastroenterol Hepatol 2016; 2016: 1-7. doi:10.1155/2016/3026563.

7. Laine L, Nagar A. Long-Term PPI Use: Balancing potential harms and documented benefits. Am J Gastroenterol 2016; 111(7): 913-15 doi: 10.1038/ ajg.2016.156.

8. Moayyedi P, Talley NJ, Fennerty MB, Vakil N. Can the clinical history distinguish between organic and functional dyspepsia? JAMA. 2006; 295:1566-76.

9. Vakil N, Moayyedi P, Fennerty MB, Talley NJ. Limited value of alarm features in the diagnosis of upper gastrointestinal malignancy: Systematic review and meta-analysis. Gastroenterology. 2006; 131:390-401.

10. Ford AC, Luthra P, Tack J, Boeckxstaens GE, Moayyedi $P$, Talley NJ. Efficacy of psychotropic drugs in functional dyspepsia: Systematic review and metaanalysis. Gut.2015. ISSN 0017-5749. doi: 10.1136/ gutjnl-2015-310721.

11. Alam L, Saeed F. Endoscopic findings in relation to age and symptoms in patients presenting with dyspepsia. Pak Armed Forces Med J. 2019; 69 (3): 44349.

12. Faintuch JJ, Silva FM, Rodrigouz TN, Barbuti RC, Hashimoto CL, Rosini AR, et al. Endoscopic findings in uninvestigated dyspepsia. BMC Gastroenterol. 2014; 14:19. DOI:10.1186/1471-230X-14-19
13. ME Ghamar Chehreh, E Shahverdi, H Khedmat, A Ghafoorian, M Amini. Endoscopic Findings in Patients with Dyspepsia in Iran. J Dig Dis 2016; 2(3): 211-19. doi:10.4172/2472-1891.100030

14. Ford AC, Marwaha A, Lim A, Moayyedi P. What is the prevalence of clinically significant endoscopic findings in subjects with dyspepsia? Systematic review and meta-analysis. Clin Gastroenterol Hepatol 2010; 8:830-7. doi: 10.1016/j.cgh.2010.05.031.

15. Hafeez, M, Sarfraz, T, Tariq $H$. Endoscopic findings in non ulcer dyspepsia; A new perspective. Pak Armed Forces Med J. 2017; 67(5), 698-701.

16. Khan N, Shabbir G, Zarif M, Khattak MI. Upper gastrointestinal endoscopic assessment of patients presenting with dyspepsia. Journal of Postgraduate Medical Institute. 2011; $21(3): 212-216$.

17. Haider SI, Ahmad J. The evaluation of frequency and seasonal variations of acid peptic disease: A seven years study. Baqai J. Health Sci. 2016; 19(1):13-17.

18. Simrén $M$, Törnblom $H$, Palsson $\mathrm{O}$, Van Tilburg $M$, Van, Tack $\mathrm{J}$ et al. Visceral hypersensitivity is associated with GI symptom severity in functional GI disorders: Consistent findings from five different patient cohorts. Gut 2018; 67(2): 255-62. doi: 10.1136/ gutjnl-2016-312361.

19. Khan Y, Mohanty S, Kumar H, Pandey S. Upper gastro instestinal endoscopic findings in patients with dyspepsia: Our experience at CIMS, Bilaspur, Chhattisgarh, India. IOSR-JDMS 2014; 13:8-12.

20. Nessa A., Hossain MR, Rahman MH, Rahman S, Mamun A, Khan J. Evaluation of 105 cases of dyspepsia by upper gastrointestinal endoscopy and ultrasonography of hepatobiliary system in a rural setting. BanglaJOL. 2019; 11(2): 25-29. doi./10.3329/ jafmc.v11i2.39819

21. Abdeljawad K, Wehbeh A, Qayed E. Low prevalence of clinically significant endoscopic findings in outpatients with dyspepsia. Gastroenterol Res Pract. 2017; 2017:3543681. doi: 10.1155/2017/3543681.

22. Yazdanpanah K, Moghimi N, Yousefinejad V, Ghaderi E, Azizi A, Nazem SF. Dyspepsia prevalence in general population aged over $\mathbf{2 0}$ in the west part of Iran. JPMA. 2012; 62(7): 672-676.

23. Sahin M, Akbulut C, Dolapcioglu C, Ozpolat E, Dabak R, Aliustaoglu M, et al. Endoscopic findings of dyspeptic patients unresponsive to proton pump inhibitors. North Clin Istanbul 2014;1(3):158-165 
24. Hussain R, Rashidian A, Hafeez A, Mirzaee N. Factors Influencing Healthcare Seeking Behaviour at Primary Healthcare Level, in Pakistan. J Ayub Med Coll Abbottabad 2019; 31(2):201-6.

25. Koh YX, Ong LW, Lee J, Wong AS. Para-oesophageal and parahiatal hernias in an Asian acute care tertiary hospital: An underappreciated surgical condition. Singapore Med J. 2016; 57(12):669-675. doi: 10.11622/ smedj.2016018.

26. Herszenyi L, Tulassay Z. Epidemiology of gastrointestinal and liver tumors. Eur Rev Med Pharmacol Sci. 2010; 14(4):249-58.

27. Andrabi RUS, Ahad WA, Yousuff M, Dawood B, Mudasir $M$, Mushtaq $S$. Endoscopic findings in persistent dyspepsia in secondary care hospital setting in North Kashmir. J Assoc Physicians India. 2019 Sep; 67(9):46-49.

28. Thyagaraja K, Bhat VS, Benny S. Endoscopic findings in uninvestigated dyspepsia patients. Int $\mathrm{J}$ Adv Med 2019; 6(4):1051-3. doi: 10.1186/1471-230X-14-19.
29. Jamil O, Sarwar S, Hussain Z, Fiaz RO, Chaudary RD. Association between functional dyspepsia and severity of depression. Jcpsp. 2016; 26(6):513-516. doi: 2353.

30. Madisch A, Andresen V, Enck P, Labenz J, Frieling $T$, Schemann M: The diagnosis and treatment of functional dyspepsia. Dtsch Arztebl Int 2018; 115: 222-32. doi: 10.3238/arztebl.2018.0222.

31. Husain N, Chaudhry IB, Afridi MA, Tomenson B, Creed F. Life stress and depression in a tribal area of Pakistan. Br J Psychiatry 2007; 190:36-41. doi:10.1192/ bjp.bp.106.022913.

32. Ishtiaq M, Imranullah, Afridi IM, Anwar M, Ali HM, Khan SA, Khan K, Ahmad Z. Frequency \& severity of depression among adult population of district Peshawar. J Med Sci 2018; 26: (2) 151-154.

33. Ventevogel P, Faiz $\mathrm{H}$. Mental disorder or emotional distress? How psychiatric surveys in Afghanistan ignore the role of gender, culture and context. Intervention. 2018; 16(3): 207-214. doi: 10.4103/intiv. intiv_60_18.

\begin{tabular}{|c|c|c|c|}
\hline \multicolumn{4}{|c|}{ AUTHORSHIP AND CONTRIBUTION DECLARATION } \\
\hline Sr. \# & Author(s) Full Name & Contribution to the paper & Author(s) Signature \\
\hline 1 & Wajeeha Qayyum & $\begin{array}{l}\text { Concept of study, Data analysis, } \\
\text { Manuscript writing. }\end{array}$ & \\
\hline 2 & M. Naveed Anwar & $\begin{array}{l}\text { Acquisition of data, revising } \\
\text { important intellectual contentent, }\end{array}$ & \\
\hline 3 & Mawara Iftikhar & $\begin{array}{l}\text { Data acquisition, Manuscript } \\
\text { writing, + Final approval of article. }\end{array}$ & \\
\hline 4 & M. Fozan Khan & $\begin{array}{l}\text { Data acquisition \& drafting } 2 \\
\text { revising manuscript + final approval }\end{array}$ & \\
\hline 5 & Mohammad Jawad & $\begin{array}{l}\text { Data analysis, Interpretation, } \\
\text { revising manuscript,Final approval. }\end{array}$ & \\
\hline 6 & Laraib Saeed & Responseve of manuscript & das \\
\hline
\end{tabular}

